\title{
PRÁTICAS DE HIGIENE E SANIFICAÇÃO EM INDÚSTRIA DE PESCADO CONGELADO
}

\author{
ROSEMERI INÊS DAMS * \\ EVANILDA TEIXEIRA ** \\ LUIZ HENRIQUE BEIRÃO $* *$
}

\begin{abstract}
Elaborou-se Manual de Boas Práticas de Higiene e Sanificação para Indústria de Pescado Congelado com o objetivo de orientar, de forma simples e prática os manipuladores e todos os envolvidos no processamento do pescado, quanto às práticas de higiene e de sanificação necessárias para a obtenção de produto de qualidade. Para tanto montou-se fluxograma do processamento de congelamento da indústria de pescado congelado, identificando-se os principais pontos críticos de controle. Levantou-se as condições higiênicosanitárias dos equipamentos, utensílios e processamento, assim como os hábitos higiênicos dos manipuladores. Acredita-se que o uso do Manual possa propiciar sanificação e condições adequadas de higiene para o trabalho, garantindo a qualidade do produtos.
\end{abstract}

\section{INTRODUÇÃO}

No processamento do pescado as condições sanitárias são essenciais para a produção de alimentos seguros e sadios (2). O pescado está sujeito a contaminações químicas provocadas pelo mercúrio, pesticidas e poluentes industriais (5), assim como microbiológicas, que poderão contribuir para sua deterioração, sendo que alguns microrganismos poderão causar toxinfecções. Além disso, a qualidade do peixe fresco pode ser influenciada pela ausência de hábitos higiênicos dos manipuladores, superfícies contaminadas como esteiras, mesas, mãos não lavadas, roupas e utensílios não sanificados (7).

Em ambiente não estéril e úmido, como no caso do processamento do pescado, que a água pode se acumular em cavidades e outros lugares, grandes populações de microrganismos podem se desenvolver e serem transferidas direta ou indiretamente para o produto $(2,4)$.

\footnotetext{
Msc.em Ciência dos Alimentos pela Universidade Federal de Santa Catarina.

** Departamento de Ciência eTecnologia de Alimentos, Universidade Federal de Santa Catarina Florianópolis, SC.
} 
O presente trabalho descreve os procedimentos adotados para a elaboração de manual de boas práticas de higiene e as recomendações apresentadas para Indústria de Pescado Congelado, visando orientar os envolvidos no processamento do pescado, quanto às práticas de higiene e de sanificação necessárias para obtenção de produtos de qualidade.

\section{MATERIAL E MÉTODOS}

\subsection{LOCAL DE COLETA DOS DADOS}

Os dados para a elaboração do manual foram coletados durante visitas realizadas a uma empresa de médio porte, localizada em Florianópolis, que processa pescado congelado.

\subsection{LEVANTAMENTO DAS CONDIÇÕES HIGIÊNICO-SANITÁRIAS}

Foram observadas as condições higiênico-sanitárias dos equipamentos, utensílios e processamento, assim como hábitos higiênicos dos manipuladores e condições gerais de limpeza e sanificação.

\subsection{FLUXOGRAMA}

A partir das observações do processamento do pescado congelado, elaborou-se fluxograma do processamento, identificando-se os principais pontos críticos de controle.

\section{RESULTADOS E DISCUSSÃo}

Como resultado das visitas realizadas à empresa foi possível estabelecer o Fluxograma 1.

A partir do fluxograma elaborou-se o manual, abordando os seguintes itens: normas e condições gerais; programa de sanificação, recomendações e cuidados pessoais; manipulação e preparação do pescado; requisitos para construção e equipamentos usados nos estabelecimentos de processamento de pescado fresco e congelado e instalações para armazenamento de resíduos e de material não comestível $(4,8,9)$. 


\title{
FIGURA 1 - FLUXOGRAMA DO PROCESSAMENTO
}

\author{
PESCA \\ $\downarrow$ \\ DESEMBARQUE \\ $\downarrow$ \\ PESAGEM \\ $\downarrow$ \\ CÂMARA FRIA \\ $\downarrow$ \\ FILETAGEM/EVISCERAÇÃO \\ $\downarrow$ \\ CONGELAMENTO EM TÚNEL A $-22^{\circ} \mathrm{C}$ \\ $\downarrow$ \\ ESTOCAGEM A $-18^{\circ} \mathrm{C}$
}

\subsection{NORMAS E CONDIÇÕES GERAIS}

As normas e condições gerais das instalações da planta processadora seguem as Boas Práticas de Manufatura (Good Manufacturing Pratices GMP), abrangendo aspectos sanitários; pertences pessoais; equipamentos; utensílios; operações sanitárias; processos; controle do pessoal.

As GMP requerem que as principais etapas dentro da planta processadora sejam ininterruptas por orifícios ou outras aberturas que possam impedir a contaminação dos alimentos ou as superfícies de contato. Os pontos mais importantes das GMP relacionadas à construção e lay out das plantas processadoras são:

- a planta processadora deve apresentar adequado espaço físico para equipamentos, instalações e estocagem de materiais;

- propiciar a separação das operações que possam contaminar os alimentos;

- fornecer adequada iluminação e ventilação;

- fornecer proteção contra insetos (11).

A proposta é assegurar que o alimento para consumo seja preparado, embalado e mantido sob condições sanitárias (6), pois a sanificação é 
necessária nas operações das planta processadoras, cujas superfícies molhadas fornecem condições favoráveis ao crescimento de microrganismos (11).

\subsection{PROGRAMA DE SANIFICAÇÃO}

O programa de sanificação envolve basicamente os seguintes processos:

- pré-enxágue com alta pressão para remoção da sujeira grossa;

- remoção física da sujeira por detergentes e ajuda mecânica;

- outro enxágue para remover os detergentes;

- aplicação de sanitizantes para prevenir a recontaminação antes do processamento.

Este programa também especifica o uso de detergentes capazes de remover produtos indesejáveis dos materiais a serem utilizados (10). Sua função é ajudar a soltar a sujeira, despreendendo-a e mantendo-a em suspensão de modo que possa ser eliminada posteriormente durante o enxágue (4). Estes devem apresentar propriedades de umedecimento, emulsificação, dissolução em água, dispersão (para evitar a formação de depósitos devido à dureza da água) e enxaguamento $(3,10)$. Os desinfectantes são classificados em bacteriostáticos, quando causam a destruição parcial ou total dos microrganismos e bactericidas, quando impedem a proliferação destes. Os desinfectantes devem ser aplicados em superfícies limpas, submetidas aos detergentes e lavagem mecânica.

\subsection{RECOMENDAÇÕES E CUIDADOS PESSOAIS}

As recomendações de higiene pessoal envolvem avaliações médicas periódicas e os seguintes cuidados:

- lavar as mãos com água e sabão, desinfectando-as antes do início do trabalho, após seu término, ou quando este for interrompido;

- manter sanitários limpos e desinfectados o tempo todo;

- evitar praticar atos não higiênicos;

- usar luvas (quando necessário) de material impermeável e adequado ao tipo de trabalho, as quais devem ser mantidas limpas, não excluindo a necessidade de se lavar as mãos;

- usar uniformes claros, os quais devem ser trocados semanalmente e mantidos em bom estado;

- manter cabelos totalmente cobertos por toucas;

- usar avental plástico nos casos em que os uniformes possam sujar-se rapidamente para evitar contaminação do produto;

- proibir o uso de jóias, de unhas postiças e de esmalte;

- não carregar objetos no uniforme, para evitar que caiam no produto; 
- não mascar cicletes, comer balas, doces ou outros alimentos na área do processamento;

- não fumar na área de estocagem e processamento de alimentos.

\subsection{MANIPULAÇÃO E PREPARAÇÃO DO PESCADO}

Durante a manipulação e preparação do pescado para processamento, os seguintes cuidados devem ser observados $(4,8,9)$ :

- separar a áreas de recepção e estocagem do pescado dos locais de preparação e embalagem do produto final;

- manter as áreas de produção sempre limpas;

- retirar os resíduos freqüentemente;

- impedir que os dejetos líquidos das operações do processamento do pescado entrem em contato com as fontes de água do estabelecimento;

- manter o chão sempre limpo e livre de sujidades;

- utilizar água de boa qualidade quimica e bacteriológica (potável nos locais de recepção, elaboração, embalagem e armazenamento), usar sistema de dosagem de cloração na água para limpeza, permitindo-se variar seu conteúdo residual (no mínimo de 20 ppm);

- manter as mesas de evisceração e filetagem limpas. Não misturar resíduos com o pescado já eviscerado e limpo ou com filés. Evitar o uso de mesas de madeira devido à facilidade de proliferação microbiana propiciada pela umidade;

- manter utensílios limpos e sanitizados;

- proceder à limpeza e sanificação do local, após o término de cada turno, suprimindo todos os resíduos e reduzindo a população microbiana da superfície que se limpou;

- limpar e sanificar facas, bandeijas e equipamentos ao final de cada turno;

- fabricar gelo com água potável e armazená-lo sob condições higiências.

3.5 REQUISITOS PARA INSTALAÇÕES FÍSICAS E EQUIPAMENTOS USADOS NOS ESTABELECIMENTOS DE PROCESSAMENTO DE PESCADO FRESCO E CONGELADO

Os requisitos para a construção de uma planta processadora de pescado fresco e congelado, assim como os equipamentos necessários, segundo o Departamento de Pescados do Canadá (1) e a International Commission on Microbiological Standars for Foods (ICMSF) (4), abrangem os seguintes itens:

- chão: superfície lavável, inclinado, sem fendas nem gretas;

- paredes: de material liso e coloração clara, sem fendas, gretas e pontos abertos; 
- portas: de superfície lisa e não absorvente, com mecanismos automáticos para abertura e fechamento;

- ventilação: adequada e controlada para evitar variações importantes na temperatura;

- iluminação: adequada para permitir a descoberta de sujidades e comprovar a eficácia da limpeza;

- toaletes: em número suficiente para atender todos os funcionários. Construídos com paredes e teto de material liso, laváveis, de cor clara e chão de material impermeável;

- instalações para lavar as mãos: convenientemente localizadas, com acionamento automático de água, sem contato manual e com fornecimento de água quente, fria, sabão em pó/líquido, secadores de ar ou toalhas descartáveis;

- água potável: com qualidade microbiológica correspondente às Normas Internacionais para Água de Bebida (OMS, 1971, citado em ICMSF, 1988);

- eliminação de efluentes: usar sistema que não contamine o abastecimento de água potável ou os alimentos;

- mesas de filetar, cortar e eviscerar: de material liso, sem fendas, recomenda-se o uso de material não corrosível, não absorvente e livre de gretas;

- equipamentos: construídos de material duradouro, não tóxico, resistente à corrosão e de superfície lisa (recomenda-se o aço inoxidável).

\subsection{INSTALAÇÕES PARA ARMAZENAMENTO DE RESÍDUOS E DE MATERIAL NÃO COMESTÍVEL $(4,8,9)$}

Os resíduos devem ser devidamente acondicionados e eliminados, impedindo-se seu acúmulo perto dos locais de processamento e/ou estocagem, para evitar o surgimento de insetos e roedores, aumentando o mal odor, além do mal aspecto. Seu acondicionamento deve ser feito em recipientes à prova d'água, de material resistente e não corrosivo, assim como as calhas para seu escoamento.

As salas de refrigeração e de congelamento devem ser mantidas limpas e sanificadas, evitando-se poças de água sobre o chão e desníveis, assim como a condensação sobre paredes, tetos ou superfícies que propicie crescimento microbiano. Além disso, deve-se controlar a temperatura por meio de termômetros automáticos. Recomenda-se o uso de dispositivos automáticos de alarme, os quais são acionados quando a temperatura sobe além do nível estabelecido previamente. 
A adoção do Manual de Boas Práticas de Higiene e Sanificação em Indústria de Pescado Congelado orienta de forma simples e efetiva todos os envolvidos no processamento do pescado congelado. $O$ mesmo foi elaborado com orientações práticas, baseadas na rotina da planta processadora, bastando para sua implantação boa orientação por parte de um especialista na área. O manual traz também orientações e especificações para a construção da planta processadora, assim como dos equipamentos. Orienta quanto ao uso dos detergentes e sanificantes e suas aplicações na planta processadora. Acredita-se que o uso do Manual possa propiciar boa sanificação e condições adequadas de higiene para o trabalho, garantindo, portanto, produtos de boa qualidade.

\section{Abstract}

A Manual of Sanification and Good Hygienic Conditions of Frozen Fish Industry with the goal to orient the handlers and all staff involved into the fish processing was elaborated. In this manual the principal critical points were established, conducing to the best conditions of sanitation and hygienic in a frozen fish processing plant. This manual helps significantly the fish processing plant offering simple and effective practices for an efficient microbial safety control for fishery products.

\section{REFERÊNCIAS BIBLIOGRÁFICAS}

1 FISH INSPECTIONS REGULATIONS SCHEDULE. Fresh and frozen fish processing establisments. Ottawa : Departament of Fisheries of Canada, 1968.

2 GABIS, D., FAUST., R.E. Controlling microbial growth in food processing environments. Food Technology, p. 81-82, Dec., 1988.

3 GIESE, H. J. Sanitation: the key to food safety and public health. Food Technology, p.74-80, Dec., 1991.

4 INTERNATIONAL COMMISSION OM MICROBIOLOGICAL STANDARD FOR FOODS. Microorganisms in foods: application of the hazard analysis and critical control points system to ensure microbiological safety and quality. Oxford : Blakwell Scientific Publications, v. 4, 1988. $357 \mathrm{p}$.

5 MARTIN, R. Contaminants in relation to the quality of sea food. Food Technology, p. 104-108, Dec., 1988. 
6 PEDRAJA, R.R. Current status of the sanitary quality of fishery products in the western hemisphere. In: CHICHESTER, C.O., GRAHM, H.D. Microbial safety of fishery products. London : Academic Press, 1973. p. 13-24.

7 PETERKIN, F.A. Sanitary state of fish and fishery products in developing countries of the eastern Caribean. In: CHICHESTER, C.O., GRAHM, H.D. Microbial safety of fishery products. London : Academic Press, 1973. p. 235-241.

8 RECOMENDED international code of pratice for fresh fish. 2.ed. Roma: FAO, 1976. 37 p. (CAC/RCP 9-1976).

9 RECOMENDED international code of pratice for frozen fish. 2.ed. Roma : FAO, 1978. 57 p. (CAC/RCP16 -1978).

10 RIEDEL, G. Controle sanitário dos alimentos. São Paulo : Atheneu, 1992. $320 \mathrm{p}$.

11 TROLLER, J.A. Sanitation in food processing. London: Academic Press, 1983. $456 \mathrm{p}$. 